\title{
A ABERTURA DIALÓGICA COMO FUNDAMENTO DE UMA ÉTICA HERMENÊUTICA
}

\author{
THE DIALOGICAL OPENNESS AS A GROUND OF A \\ HERMENEUTIC ETHICS
}

\begin{abstract}
Marcos André Webber ${ }^{1}$
Resumo: O presente artigo tem como objetivo empreender uma reflexão acerca das condições da relação ética autêntica, justificando que a abertura dialógica, a partir da qual Gadamer estabelece a possibilidade do reconhecimento do outro enquanto outro, remete à pré-compreensão, a qual não foca em um o que, mas em um como do nosso comportamento e em um quem do nosso caráter. Através dos recursos conceituais do pensamento hermenêutico gadameriano, buscaremos analisar as condições do que torna autêntica uma relação, mostrando que a abertura ao diálogo permite não apenas o reconhecimento do tu de fato como um tu, mas é o que eleva o homem à sua humanidade. Ao final, concluiremos que a aptidão ao diálogo não se refere à habilidade técnica de comunicação ou etiqueta, mas a uma maneira de ser que nos possibilita responder propriamente aos impulsos para compreender que nos confronta no curso de nossos envolvimentos.

Palavras-chave: ética; hermenêutica; abertura dialógica; compreensão.

Abstract: This paper aims to undertake a thinking on the conditions for an authentic ethical relationship, justifying that the dialogical openness, from which Gadamer establishes the possibility for the recognition of the other as other, refers to pre-understanding, which do not focus on what, but on how of our behavior and on who of our character. Through conceptual resources of Gadamer's hermeneutical thought, we will seek to analyse the conditions of what makes authentic an relationship, showing that the openness to dialogue allows not only the recognition of Thou actually as a Thou, but it is what elevates the man to its humanity. Lastly, we shall conclude that an aptitude to dialogue do not refer to an technical skill in communication or etiquette, but to an way of being that allows us to answer properly the impulses to understand that confront us in the course of our involvements.
\end{abstract}

Recebido: 03/2017 Aprovado: 09/2017

Keywords: ehics; hermeneutics; dialogical openness; understanding.

\section{Considerações Iniciais}

O objetivo central do presente trabalho está voltado para uma reflexão acerca das condições do que se poderia definir como uma relação ética autêntica, sustentando-se que a abertura dialógica, a partir da qual Gadamer estabelece a possibilidade do reconhecimento do outro enquanto outro, remete à pré-compreensão focada em um como e um quem, mas não em um o que. Ao passo que a tradição do pensamento ético-filosófico tem se focado muito mais em o que fazer, a proposta de Gadamer reflete um como do nosso comportamento, e quem somos em nossas relações com o outro.

Assim, através dos recursos conceituais do pensamento hermenêutico gadameriano, buscaremos analisar as condições do que torna autêntica a relação entre o eu e o tu, mostrando que a abertura ao diálogo permite não

\footnotetext{
${ }_{1}^{1}$ Doutorando em Filosofia pela Universidade do Vale do Rio dos Sinos (UNISINOS), Mestre em Filosofia pela Universidade de Caxias do Sul (UCS). Filiação acadêmica: Universidade do Vale do Rio dos Sinos (UNISINOS). Bolsista CAPES/PROSUP. E-mail: marcoswebber@terra.com.br
} 
apenas o reconhecimento do tu de fato como um $t u$, mas é o que eleva o homem à sua humanidade. Importa notar, nesta perspectiva, que tanto o vínculo ético que podemos manter com o outro, quanto o reconhecimento do outro como um parceiro, se efetivam em contextos de vida socialmente situados, cujo conteúdo consiste no estabelecimento de uma relação autêntica com o outro como um tu.

Dessa forma, a fim de desenvolver o argumento que aqui nos propomos, o presente trabalho se desenvolverá em três partes. Inicialmente serão apresentadas as três maneiras de se fazer a experiência do tu exploradas por Gadamer em Verdade e método I, justificando os motivos pelos quais a experiência hermenêutica deve ser compreendida como a forma autêntica e mais completa de experienciarmos o tu. A seguir buscaremos mostrar que a experiência hermenêutica consiste em uma abertura dialógica, a qual permite o reconhecimento do outro como alguém que tem algo a nos dizer. Em um momento final, buscaremos evidenciar que a abertura ao outro não tem a ver com a realização de uma essência presumida e pré-dada. Uma vez que a compreensão não foca em um o que, mas em um como e um quem, trataremos de argumentar que as condições de uma relação ética autêntica não dizem respeito a o que fazer, mas a um como do nosso comportamento e a quem somos em nossas relações com o outro.

\section{Sobre a experiência do outro em Verdade e método I}

No capítulo $O$ conceito de experiência e a essência da experiência hermenêutica, de Verdade e método I, ao explorar o conceito de experiência, Gadamer chama a atenção para três maneiras de se fazer a experiência do tu. A intenção do filósofo alemão é mostrar que existe uma maneira mais elevada e completa de fazermos a experiência do $t u$, que em última instância se apresentaria como uma relação autêntica de si mesmo com o outro. E uma adequada compreensão das implicações desta relação autêntica pode dar indicativos da contribuição que a hermenêutica pode fornecer na análise do comportamento ético.

Conforme dispõe Gadamer, a primeira maneira de se fazer a experiência do tu é tratando-o como objeto. Nesta forma de experiência, o comportamento do outro "nos serve como meio para nossos fins, como qualquer outro meio. Moralmente falando, esse comportamento com relação ao tu significa a referência ao egoísmo puro e simples e contradiz a determinação moral do homem" (GADAMER, 2011, p. 468). Assim, a primeira maneira de se relacionar com o outro nada mais é do que uma redução do outro a objeto de cálculo, como um instrumento que se pode dominar totalmente, sem espaço para 
compreendê-lo de fato como outro.

A segunda maneira de se fazer a experiência e compreender o $t u$, nas palavras de Gadamer, "consiste em reconhecê-lo como pessoa, mas, apesar de incluir a pessoa na experiência do tu, a compreensão deste continua sendo um modo de referência a si mesmo"(GADAMER, 2011, p. 469). Há, neste caso, uma autorreferência que resulta da aparência dialética da própria relação eu-tu. Dessa forma, a relação entre o eu e o tu não é imediata, mas reflexiva. A pretensão de conhecer por si mesmo, e antecipadamente, a pretensão do outro, subtrai as próprias pretensões do outro. Assim, embora seja mais adequada do que a primeira maneira de experienciar o outro, uma vez que ao menos reconhece o outro como pessoa, esta segunda forma de relação ainda não reconhece de fato o outro enquanto outro, e por isso ela não espelha uma relação que reconheça o tu enquanto tu.

Mas há uma terceira maneira de fazermos a experiência do tu, a experiência hermenêutica, a qual Gadamer determina como sendo a mais elevada, justamente por possibilitar a experiência do tu exatamente como um tu. Em Verdade e método I, esta experiência hermenêutica está descrita da seguinte forma:

\begin{abstract}
na relação inter-humana, o que importa é experimentar o tu realmente como um tu, isto é, não passar ao largo de suas pretensões e permitir que ele nos diga algo. Para isso é necessário abertura. Mas, por fim, esta abertura não se dá só para aquele a quem permitimos que nos fale. Ao contrário, aquele que em geral permite que se lhe diga algo está aberto de maneira fundamental. Sem essa abertura mútua, tampouco pode existir verdadeiro vínculo humano. A pertença mútua significa sempre e ao mesmo tempo poder ouvir uns aos outros. Quando dois se compreendem, isto não quer dizer que um "compreenda" o outro, isto é, que o olhe de cima para baixo. E igualmente, "escutar alguém" não significa simplesmente realizar às cegas o que o outro quer. Agir assim significa ser submisso. A abertura para o outro implica, pois, o reconhecimento de que devo estar disposto a deixar valer em mim algo contra mim, ainda que não haja nenhum outro que o faça valer contra mim (GADAMER, 2011, p. 471-472).
\end{abstract}

Depreendem-se, da citação acima, ao menos quatro características fundamentais da experiência hermenêutica do $t u$, possibilitadas justamente pela ideia de abertura ao outro, e que merecem certo destaque em nossa abordagem. A primeira diz respeito ao fato de que a experiência hermenêutica é a única que nos permite experienciar o tu enquanto tu. Ao passo que a primeira maneira de fazermos a experiência do tu concebe o outro como um objeto de cálculo, e a segunda compreende-o através de uma autorreferência a si mesmo - o que não significa o reconhecimento o outro realmente enquanto outro -, a experiência hermenêutica é a única que almeja o reconhecimento do 
outro em suas próprias pretensões, como alguém que tem algo a nos dizer.

A segunda característica relaciona-se ao deixar-se tocar pela experiência do outro. Nas relações com o outro, o eu precisa estar disposto a deixar-se tocar pelo que o outro tem a dizer. Uma terceira característica consiste na capacidade e exercício de ouvir uns aos outros, o que requer não apenas uma certa disposição para escutar o outro em suas pretensões, mas de colocar tal disposição em prática. Da mesma forma, o outro deve estar disposto a ouvir o que nós temos a lhe dizer. A quarta característica aqui destacada, e que se encontra no final da citação do texto gadameriano acima destacado, refere-se à necessidade de estar disposto a deixar a valer em mim algo contra mim. Esta pode talvez ser considerada a expressão máxima do reconhecimento do outro enquanto outro, na medida em que deixo valer contra mim algo que o outro me diz, mesmo que seja algo contrário às minhas pretensões. Em outras palavras, significa dizer que, através da experiência hermenêutica do outro, não apenas reconheço o tu enquanto $t u$, mas o tomo como alguém igual a mim, a quem devo ouvir pois tem algo a me dizer.

Dessa forma, embora tenhamos apontado alguns dos motivos que levaram Gadamer a considerar a experiência hermenêutica como a forma mais completa e elevada de experienciar o $t u$, ainda resta a questão de justificar por que esta forma de experiência é autêntica. Para tanto, deve-se antes compreender que uma experiência autêntica do tu não deveria se dar em contextos universalizáveis ou generalizáveis. Pelo contrário, as experiências e as relações com o outro ocorrem sempre em situações particulares. Dito de outra forma, a experiência nunca se dá por um eu universal e abstrato, mas por um eu singular, junto a um tu também singular. E tratar o que é singular por meio de uma universalização, ou de uma generalização, seria incorrer na objetificação da própria vida, o que ocultaria as particularidades sempre implicadas nas nossas relações fáticas sociais. Daí por que a experiência hermenêutica é a única capaz de refletir o sentido da relação autêntica entre um eu e um tu singulares.

Esta singularização, contudo, pode ser melhor compreendida se voltarmos nosso olhar à distinção que Heidegger faz, em Ser e tempo, entre os sentidos atribuídos ao mundo pelos modos de ser autêntico e inautêntico. Muito embora o impessoal forneça um sentido geral da relação entre um eu e um tu, o modo de ser inautêntico não é capaz de alcançar a singularidade de cada relação. Isso ocorre porque, conforme explica Heidegger, "o impessoal que responde a pergunta pelo quem do Dasein cotidiano, é o ninguém a que todo Dasein já está entregue sempre em seu ser com os outros" (HEIDEGGER, 2006, p. 128).

Por consequência, uma relação estabelecida sobre a base da impessoalidade não pode ser compreendida como uma relação autêntica entre 
o eu e o tu, mas uma relação cujos interlocutores não são ninguém. E na medida em que se percebe que cada relação está sempre inserida em contextos de sentido que exigem levar em conta as particularidades que caracterizam os sujeitos implicados na relação, tal singularidade não é abarcada pelo impessoal.

Já no modo de ser autêntico, ao contrário do impessoal, o sentido da relação se torna uma construção que vai se dar em cada caso. Enquanto modificação do modo de ser inautêntico, o modo de ser autêntico abre espaço para novos sentidos, mais ligados à existência singular do Dasein. A este aspecto, a autenticidade se refere à tensão entre socialização e singularização, e não um rompimento com o mundo social enquanto tal (HATAB, 2000, p. 27). Conforme explica Guignon (1993), na medida em que se constitui como uma modificação na maneira de compreender o mundo, a autenticidade representa uma forma mais rica e completa de participação no contexto público. Nas palavras do autor,

Heidegger afirma que a autenticidade "não separa o Dasein do seu mundo"; o mundo "não se torna outro em seu conteúdo, nem o círculo dos Outros é substituído por um novo" (SZ 344). De fato, uma vez que as nossas próprias histórias de vida são inseparáveis de um texto mais amplo de um mundo que compartilhamos, a autenticidade pode nada mais ser do que uma forma mais completa e mais rica de participação no contexto público (GUIGNON, 1993, 228).

Justamente porque no modo de ser inautêntico o sentido do mundo e das relações já está previamente dado, a inautenticidade não espelha a singularidade que caracteriza o Dasein. E na medida em que se busca neste primeiro momento colocar em evidência aquilo que de fato caracteriza uma relação autêntica, torna-se fundamental compreender quem são o eu e o tu implicados na relação. Assim, enquanto que apenas o modo de ser autêntico é capaz de indicar o que torna o Dasein singular, em detrimento do modo de ser inautêntico, é unicamente sobre a base do si mesmo autêntico que passamos a compreender adequadamente o que torna autêntica a experiência que podemos ter do outro.

Estabelecida, portanto, a maneira mais adequada de fazermos a experiência do outro, é preciso olhar mais de perto a forma pela qual a experiência hermenêutica se realiza na vida fática, e especialmente no encontro fático com o outro. É com este objetivo que passamos agora a tratar mais especificamente de um tipo de abertura de si mesmo ao outro, a qual pode ser denominada abertura dialógica, ou de aptidão ao diálogo. 


\section{A experiência hermenêutica como abertura dialógica}

Na leitura de Kögler (2014), a experiência hermenêutica descrita por Gadamer consiste em uma atitude de abertura dialógica, que reconhece plenamente o outro através da abertura de si mesmo à reivindicação do outro. Trata-se, segundo o autor, de "um ethos da abertura como fundamentos sobre os quais o respeito mútuo e as relações verdadeiras podem florescer" (KÖGLER, 2014, p. 15). Em outras palavras, pode-se dizer que o ethos hermenêutico consiste na abertura em direção ao espaço dialógico entre si mesmo e o outro. O conceito de abertura assume a figura central, compreendida como uma disposição dialógica em escutar o outro em suas próprias pretensões.

Note-se, neste contexto, que a exigência ética não repousaria sobre a necessidade de se alcançar um consenso, mas sobre a abertura a um espaço de diálogo. A experiência hermenêutica autêntica diz respeito à abertura e à escuta ao outro, independentemente de se chegar a um consenso ou não. Muito embora o resultado do diálogo muitas vezes possa colocar os interlocutores frente a diferenças intransponíveis, isso de forma alguma reduz a importância do diálogo. Como já mencionado anteriormente, reconhecer que o outro tem algo a dizer, mesmo que seja algo contra nós, faz parte de um comportamento autêntico frente às relações sociais.

Quanto ao que se deve entender como diálogo, esclarece Gadamer que "um diálogo é, para nós, aquilo que deixou uma marca. O que perfaz um verdadeiro diálogo não é termos experimentado algo de novo, mas termos encontrado no outro algo que ainda não havíamos encontrado em nossa própria experiência de mundo" (GADAMER, 2004, p. 247). Desse modo, Gadamer explica que não é qualquer tipo de conversação que deve ser tomada de fato como um diálogo. Diferentemente das conversas formais e desinteressadas do cotidiano, um verdadeiro diálogo constrói uma espécie de comunhão, e por isso possui uma força transformadora, capaz de produzir mudanças no modo de ser e de compreender dos interlocutores.

Isso porque o diálogo requer não apenas um abrir-se ao outro, o que implica escutar o que o outro tem a nos dizer, mas também uma aproximação mútua, sem a qual inexiste qualquer tipo de vínculo humano (GADAMER, 2011, p. 472). E é justamente porque sem escuta não é possível o diálogo, que a capacidade constante de voltar ao diálogo e de ouvir o outro que, segundo Gadamer, parece ser "a verdadeira elevação do homem à sua humanidade" (GADAMER, 2004, p. 251). Na medida em que nossa apercepção do mundo permanece privada, assim como nossos impulsos e nossos interesses nos individualizam, o diálogo representa uma espécie de expansão da nossa individualidade, permitindo-nos encontrar no outro algo que ainda não 
havíamos encontrado em nossa própria experiência de mundo (GADAMER, 2004, p. 246-247).

Em um verdadeiro diálogo, no qual os parceiros colocam seus preconceitos em risco, dando a primazia à escuta ao que o outro tem a dizer, o diálogo se torna um tipo de questionamento compartilhado, sendo cada parceiro um co-intérprete. Como destaca Gill, "o ethos aqui deve considerar o outro como um co-sujeito, e não apenas um 'tu'" (GILL, 2015, p. 16). Há um vínculo no diálogo que vai além da mera troca de informações, exigindo uma disposição dos interlocutores em colocar em questão a si próprio e suas próprias convicções.

Mas é preciso observar, e esta talvez seja uma das principais contribuições da hermenêutica na busca de um fundamento para a ética, que todo diálogo e toda relação com o outro se dão em contextos de sentido compartilhados. Quando falamos em uma abertura a um espaço de diálogo, é fundamental compreender que este "espaço" é previamente marcado pelos contextos culturais e sociais a partir dos quais a experiência do tu se torna possível. Na linguagem gadameriana, pode-se afirmar que o agente está desde sempre inserido em uma tradição, a qual é definida por Kögler como "o contexto intersubjetivo vivido das práticas culturais e sociais que definem a compreensão compartilhada dos agentes sobre si mesmos, os outros e o mundo" (KÖGLER, 2015, p. 313).

A aptidão ao diálogo, neste aspecto, não se refere à habilidade técnica de comunicação ou etiqueta, mas a uma maneira de ser que nos possibilita responder propriamente aos impulsos para compreender que nos confronta no curso de nossos envolvimentos. Conforme explicita George, Gadamer propõe esta aptidão como

um emblema da nossa capacidade de abrir-nos ao que não somos, de nos
envolvermos com os outros de forma que nos relacionemos com eles na
exterioridade do seu próprio ser, e, assim, quando dialogamos, ambos os
ouvimos e falamos não apenas em nossos próprios termos mas a partir das
exigências da nossa cena do encontro com eles (GEORGE, 2014, p. 110-
111).

Está presente sem dúvida uma influência de Heidegger, especialmente no modo como este coloca em evidência em Ser e tempo o mundo prático e social compartilhado no qual o Dasein está desde sempre e primariamente inserido. Estamos sempre auto-implicados na compreensão que temos do mundo, o que sugere uma espécie de entrelaçamento entre considerações epistêmicas e éticas, e que em última análise se refere à nossa constituição ontológica enquanto seres humanos. Daí por que compreender o outro não seria apenas um ato cognitivo, mas uma renovação da nossa co-existência 
social.

O reconhecimento hermenêutico do outro é compreendido como um projeto em andamento que encontra sua realização ética na abertura real ao que o outro tem a dizer. E uma vez que tal projeto, como já mencionado, está sempre em andamento, o reconhecimento igualitário do outro não deveria ser compreendido como um imperativo categórico. Como responder à reivindicação do outro é um esforço que se não pode ser realizado por uma fórmula mágica (KÖGLER, 2015, p. 319). Pelo contrário, o reconhecimento do outro se dá em cada caso, o que exige que sejam levados em conta não apenas os contextos particulares nos quais as relações ocorrem, mas a própria pré-compreensão que constitui ontologicamente o si mesmo e o outro.

Os modos pelos quais as relações se dão na vida fática não são algo que possa ser enumerado ou elencado previamente em todas as suas possibilidades. Pelo contrário, o modo pelo qual surgem as relações depende de elementos que nem sempre podem ser preconcebidos à exaustão. Se por um lado as relações estão sempre situadas historicamente em contextos de sentido compartilhados, de outro deve-se ter em vista que a pré-compreensão dos envolvidos também está sempre implicada na relação. Neste contexto, estabelecer condutas com base em imperativos categóricos - ou fórmulas mágicas, como define Kögler - implica deixar de lado as particularidades de cada relação singular, em benefício a normas generalizáveis que nem sempre são capazes de explicá-las, especialmente por submeterem à objetificação o que está envolvido na própria relação.

Tomada como uma espécie de pano de fundo essencialmente intersubjetivo, a pré-compreensão hermenêutica permite uma contribuição para o fundamento da ética em uma sofisticada concepção de comunidade dialógica, em que comunidade não deve ser entendida como uma totalidade social abrangente que subjuga o si mesmo e o torna um com os outros, nem como a noção de um conjunto de agentes distintos que contingencialmente formam vínculos sobre o espaço que aparentemente separa seus inescapáveis si mesmos individuais. Muito pelo contrário, só é possível compreender-se a si mesmo porque se está incorporado a uma compreensão que implica um reconhecimento e vínculo pré-existente com o outro. "O outro, ou melhor: a relação intersubjetiva básica com o outro, é uma pressuposição para a própria existência assim como a própria capacidade cognitiva" (KÖGLER, 2015, p. 314). Só podemos ter uma compreensão de nós mesmos e do mundo porque estamos inseridos em uma compreensão que funciona como um pano de fundo em nossas relações, a qual aponta para um reconhecimento implícito e um vínculo pré-existente com o outro. Há, neste sentido, uma relação intersubjetiva básica com o outro que é uma pressuposição para a própria existência. Tratase, assim, de uma prioridade ontológica da relação intersubjetiva antes de 
qualquer relação com o mundo e consigo mesmo, que se mostra condição de possibilidade para a compreensão e a interpretação.

Observe-se, nesta perspectiva, que a pré-compreensão hermenêutica já traz em si mesma uma espécie de reconhecimento e vínculo ao outro. Por isso a experiência do tu não se dá unicamente no encontro fático com o outro. Pelo contrário, o outro só se apresenta como um tu em razão da relação intersubjetiva possibilitada pela constituição ontológica do ser humano. Nesta relação, o outro não fica reduzido a mero objeto do conhecimento. Ele surge como alguém com quem compartilhamos práticas e contextos, motivo pelo qual compreendê-lo não se reduz a um ato cognitivo. Conforme explica Kögler, "compreender o outro epistemicamente é assim reconhecer o outro como um parceiro racional no diálogo, e assim também reconhecer o outro eticamente como um igual" (KÖGLER, 2015, p. 316).

Nestes termos, a construção de uma ética hermenêutica fundada na abertura dialógica reconhece que tanto o vínculo ético com o outro quanto o reconhecimento do outro como um parceiro efetivam-se em contextos de vida socialmente situados. Ao passo que as interpretações objetificadoras do homem decorrentes da tradição metafísica são incapazes de alcançar o verdadeiro e mútuo relacionamento com o outro - uma vez que seu arcabouço conceitual recorre a universalizações e generalizações -, a abertura ao espaço de diálogo com o outro possibilita estabelecer uma relação autêntica e singular com o outro como um tu.

Mas se nenhuma teoria, esquemas ou regras dadas antecipadamente são adequadas à vida fática, cabe questionarmos os meios pelos quais é possível à ética hermenêutica alcançar a singularidade das relações, dos comportamentos e da experiência do outro. A resposta à questão está ligada ao problema da compreensão e da aplicação. O que está em jogo é perceber que a compreensão não foca em um o que, mas em um como e em um quem implicados na relação. E é com o intuito de tentar explicitar o modo da compreensão que antecede o comporta-se perante 0 outro que será desenvolvida a parte final do presente trabalho.

\section{A compreensão e a aptidão ao diálogo}

$\mathrm{Na}$ busca dos fundamentos do agir, a filosofia tem endereçado sua reflexão à tentativa de apresentar justificações para as ações, cujo objetivo último se traduz na definição da melhor forma de dirigirmos o nosso agir em cada situação. A este aspecto, frequentemente os filósofos voltam-se a um 0 que, cuja pretensão diz respeito à definição da ação a ser praticada em determinadas circunstâncias. Em última instância, pode-se dizer que a história 
da filosofia moral tem se dedicado à busca de justificativas que sustentem $o$ que deve ser feito em cada caso, ou, dito de outro modo, a determinação de qual ação deve ser praticada nas mais diversas situações, almejando alcançar uma espécie de certeza no que se refere às melhores ou piores maneiras de agir sob certas circunstâncias.

Gadamer, contudo, não partilha desta ideia no que diz respeito à tarefa da filosofia no tratamento da conduta humana. Isso porque "o que está em jogo na hermenêutica é a compreensão ontológica do que 'é', e não um abstrato, desconectado e presunçoso 'deve'" (KÖGLER, 2014, p. 10). Pois isto é exatamente o que Gadamer menciona no prefácio à segunda edição de Verdade e método I, ao afirmar: "Minha verdadeira intenção, porém, foi e continua sendo uma intenção filosófica: $O$ que está em questão não é o que fazemos, o que deveríamos fazer, mas o que nos acontece além do nosso querer e fazer" (GADAMER, 2011, p. 14). E mais adiante complementa Gadamer, afastando seu interesse filosófico de uma ética normativa: "A função do pregador moral, nas vestes de investigador, tem algo de absurdo. Absurda é igualmente a pretensão do filósofo que deduz, a partir de princípios, como deveria transformar-se a 'ciência' para poder ser legitimada filosoficamente"(GADAMER, 2011, p. 15).

Ocorre que, se tomada sob uma perspectiva hermenêutica, a compreensão já representa um retorno à vida fática que atribui sentido ao mundo. Há uma tentativa de superação, tanto da noção de que a compreensão precisa ser aplicada, quanto da cisão entre teoria e prática, visto que a compreensão hermenêutica não necessita de aplicação. Para Gadamer, compreensão já é aplicação, o que o filósofo alemão explica do seguinte modo: "não se trata de uma aplicação ulterior de algo já compreendido em si mesmo a outra coisa distinta, mas a própria aplicação é a autêntica compreensão do assunto para aquele que tenta compreender" (DUTT, 1998, p. 41). Neste contexto, a aplicação não deve ser entendida como um objetivo da práxis hermenêutica, mas como um elemento implícito em toda compreensão. Quem compreende forma parte da mesma coisa que compreende.Como bem esclarece Schmidt,

a compreensão nunca é encontrada separada da vida fática; ela não se coloca acima dela como uma teoria, mas nem deve ser definida como uma questão de práxis. Preferivelmente, a compreensão é um ato contínuo que é renovado a todo instante; é um modo de vida que é informado pela história, linguagem e hábitos - todas as realidades da situação da vida fática. Enquanto tal, a compreensão não deve ser compreendida como uma teoria - embora uma teoria possa eventualmente resultar da compreensão - nem deve ser compreendida como uma ação [...]. Preferivelmente, a compreensão forja o centro, o "quem", que nos tornamos; ela se torna a 
base para como é que passamos a conhecer e articular conceitualmente nosso mundo e a nós mesmos (SCHMIDT, 2012, p. 42).

Importa ainda notar que, do mesmo modo que a compreensão não deve ser entendida como aplicação de uma teoria, ela não consiste na realização de uma essência. Se por um lado a compreensão constitui o ser humano, por outro é preciso perceber que as possibilidades que somos capazes de pôr em prática não são condicionadas por uma essência presumida pré-dada. Evidentemente, o que se encontra na base desta discussão é uma determinada concepção de ser humano. E nesta perspectiva, merece destaque a crítica de Heidegger à tradição humanista, especialmente no que se refere à ideia de uma essência prévia como fundamento da humanidade do homem.

Na Carta sobre o humanismo, Heidegger (1973) sustenta que a tradição humanista busca meios de fundamentar o valor da nossa existência na alegada visão da essência metafísica dos seres humanos. O humanismo, nesse sentido, alinha-se ao essencialismo metafísico, visto que a "humanidade do ser humano" é compreendida como consistir em nada além de "sua essência" (GEORGE, 2014, p. 106). Para Heidegger, contudo, os seres humanos não são caracterizados por uma essência prévia, mas pela existência, motivo pelo qual sua inestimabilidade não decorre da responsabilidade em realizar uma essência presumida e pré-dada. Esclarece George que,

em contraste com o humanismo, no qual a possibilidade própria dos seres humanos é sempre já dada antecipadamente por uma alegada essência, Heidegger sustenta que as possibilidades próprias a nós somente são concedidas pelo ser na medida em que ele se renova no nosso envolvimento com os entes encontrados nas situações sempre singulares e dinâmicas nas quais estamos lançados (GEORGE, 2014, p. 107).

O que está em questão, em última instância, é o fato da compreensão não focar em um o que, mas em um como e um quem. Ao passo que tanto a noção de aplicação prática de uma teoria, quanto a concepção metafísica essencialista do ser humano, estão voltadas a um o que, a compreensão foca no como do nosso comportamento, e no quem do nosso caráter. É o que explica George:

A compreensão não foca em um "o que" - nem o que a teoria nos concede de conhecimento nem qual intenção ou fim queremos perseguir. Ao contrário, a compreensão diz respeito ao "como" do nosso comportamento e a "quem" do nosso caráter. Ela fala ao "como" do nosso comportamento através da realização de padrões conceituais de articulação que guiam nosso envolvimento com o mundo e com os outros; e, ela fala ao "quem" do nosso caráter como viemos a ser definidos através da expressão e 
desenvolvimento destes padrões (GEORGE, 2014, p. 114).

Nesta perspectiva, o problema relativo às condições para uma relação autêntica com o outro não se resolve pela determinação de o que se deve fazer. Uma vez que a singularidade das relações, a partir das quais emergem as questões morais, exige que seja levada em consideração a compreensão que constitui o ser humano, o objeto da análise deve voltar-se ao como que caracteriza o comportamento, e a quem somos em nossas relações com 0 outro. Na esteira da abordagem gadameriana, a abertura ao diálogo possibilita a reconstrução dialógica de um "imperativo ético" que reconhece o outro como um fim em si mesmo, como um sujeito que é em si mesmo uma fonte de crenças e suposições (KÖGLER, 2015, p. 316). Tal imperativo, contudo, não nos diz o que fazer, mas nos indica o modo autêntico de nos comportarmos frente o outro. Em outras palavras, a abertura ao espaço de diálogo permite ao homem "ser si mesmo autêntico" no reconhecimento do outro enquanto um tu que tem algo a lhe dizer. E justamente porque a aptidão ao diálogo reconhece o outro como outro, ela nos eleva à nossa humanidade.

Esta aptidão ao diálogo, em grande medida, pode ser considerada a virtude ou excelência própria da compreensão, concebida como um problema de comportamento e caráter (GEORGE, 2014, p. 114). É que a aptidão ao diálogo não tem a ver com o conhecimento prévio do que queremos dizer ou à habilidade de dizer, mas à abertura perceptiva ao que ouvimos e dizemos. Uma vez que a mera observação de regras universais, ou a realização de uma essência presumida e pré-dada, são incapazes de abarcar as particularidades da vida fática e dos contextos de sentido nos quais ocorrem as relações sociais, o cultivo da nossa habilidade de nos envolvermos responsavelmente requer o enfrentamento do problema da compreensão.

Neste contexto, estabelecer as melhores ou piores formas de tratar o outro, e determinar o modo como devemos responder à reivindicação do outro, exige um esforço contínuo, que não pode se resolver por regras abstratas com pretensão de universalização. Muito embora a objetividade das leis morais evidencie algo sobre as relações humanas, ela não é suficiente para dar conta das exigências que a ética faz perante a vida. Na medida em que as questões éticas emergem sempre em situações particulares, torna-se fundamental voltarse antes aos contextos de sentido a partir dos quais as questões éticas surgem.

Se por um lado uma ideia de ética hermenêutica pode representar uma crise em relação aos fundamentos da ética, de outro ela coloca em questão a importância dos contextos sociais e culturais para a abordagem filosófica do tema. O desafio de uma ética hermenêutica consiste justamente em fazer a análise do diálogo frutífera para uma abordagem que guie a ação humana. A exigência gadameriana de abertura ao espaço de diálogo em momento algum 
prescreve o que deve ser dito, nem o que deve ser feito. A disposição para ouvir o que o outro tem a nos dizer em suas próprias pretensões revela apenas o modo como, de forma autêntica, devemos nos comportar e externar quem somos na experiência que fazemos do outro enquanto outro.

Assim, a abertura dialógica surge como uma tentativa de explicar o que constitui uma relação ética autêntica, sem deixar de levar em conta o contexto social no qual tais relações ocorrem. Ao passo que muitas vezes a objetividade das regras morais conduz a uma objetificação da vida humana, e com isso deixa-se de levar em conta os contextos compartilhados de sentido que precedem todo comportamento humano, uma ética hermenêutica busca não apenas tratar o outro em sua individualidade, mas reconhecer a sua humanidade na prática dialógica da compreensão e da interpretação.

\section{Considerações Finais}

No presente trabalho buscou-se justificar que a abertura dialógica, enquanto fundamento para a construção de uma ética hermenêutica, não apenas possibilita o reconhecimento do outro de fato como um outro, mas mostra-se como condição de uma relação autêntica com o tu. Na medida em que o nosso comportamento perante o outro e o mundo depende da nossa précompreensão, a qual não foca em um o que deve-se fazer, mas no como do nosso comportamento e no quem do nosso caráter, a abertura dialógica ao outro não se apresenta apenas como condição para uma relação ética autêntica, mas evidencia como nos comportamos e quem somos nós em nossas relações com o outro.

Ao passo que a pretensa certeza da tradição metafísica em prescrever regras universais incorrem na objetificação e generalização da vida fática, emerge o problema da compreensão como uma tentativa de alcançar as particularidades das situações a partir das quais as questões éticas emergem. Nesse sentido, importa notar que as relações estão sempre situadas em contextos de sentido compartilhados, assim com o espaço para o diálogo também encontra-se previamente marcado pelos contextos culturais e sociais a partir dos quais a experiência do tu se torna possível.

O apelo de Gadamer para nos elevarmos à nossa humanidade não é um pedido para realizarmos uma essência pré-dada, mas um apelo para voltarmos nossa atenção para aquilo que nos torna mais humanos, e que revela o nosso envolvimento com o mundo. Através da capacidade constante de voltar ao diálogo e de ouvir o outro, passamos a experienciar o tu realmente como um $t u$, e com ele nos relacionarmos de forma autêntica. A aptidão ao diálogo, neste aspecto, não se refere à habilidade técnica de comunicação ou etiqueta, mas a 
uma maneira de ser que nos possibilita responder propriamente aos impulsos para compreender que nos confronta no curso de nossos envolvimentos. Deixar-se tocar pela experiência do outro e reconhecê-lo em suas próprias pretensões constituem condições essenciais para a construção de uma ética hermenêutica, que almeja não apenas alcançar a singularidade das relações sociais, mas elevar-nos à nossa humanidade em nossa compreensão e interpretação.

\section{Referências}

DUTT, Carsten. En Conversación con Hans-Georg Gadamer (Hermenéutica Estética - Filosofía Prática). Trad. de Teresa Rocha Barco. Madrid: Tecnos, 1998.

GADAMER, Hans-Georg. Verdade e método I. 11. ed. Petrópolis, RJ: Vozes, 2011.

Verdade e método II. 2. ed. Petrópolis, RJ: Vozes, 2004.

GEORGE. Theodore. The responsibility do understand. Phenomenological perspectives on plurality. v. 12. p. 103-120. 2014.

GILL, Scherto. "Holding oneself open in a conversation" - Gadamer's philosophical hermeneutics and the ethics of dialogue. Journal of Dialogue Studies. v. 3 n. 1. p. 9-28. 2015.

GUIGNON, Charles. Autenticity, moral values and psychoterapy. IN: The Cambridge Companion To Heidegger. New York: Cambridge University Press, 1993.

HATAB, Lawrence J. Ethics and finitude: Heideggerian contributions to moral philosophy. Maryland: Rowman and Littlefield Publishers, 2000.

HEIDEGGER, Martin. Sein und Zeit. 19. ed. Tübingen: Max Niemeyer Verlag, 2006.

Carta sobre o humanismo. Trad. de Ernildo Stein. São Paulo: Abril S/A Cultural e Industrial, 1973.

KÖGLER, Hans-Herbert. The crisis of a hermeneuthic ethic. Philosophy today. 
v. 58, n. 1. p. 9-22, 2014.

. Ethics and community. The Routledge Companion to Hermeneutics. New York: Routledge, 2015. p. 310-323.

SCHMIDT, Dennis J. Hermeneutics as original ethics. Difficulties of Ethical Life. New York: Fordham University Press, 2008.

On the Sources of Ethical Life. Research in Phenomenology, v. 42, p. 35-48, 2012. Disponível em http://booksandjournals.brillonline.com/content/journals/10.1163/156916412x62 8739. Acesso em 17. Out. 2016. 